Bulk velocity measurements by video analysis of dye tracer in a macro-rough channel

This content has been downloaded from IOPscience. Please scroll down to see the full text.

2014 Meas. Sci. Technol. 25035003

(http://iopscience.iop.org/0957-0233/25/3/035003)

View the table of contents for this issue, or go to the journal homepage for more

Download details:

IP Address: 128.178.27.45

This content was downloaded on 22/04/2014 at 08:34

Please note that terms and conditions apply. 


\title{
Bulk velocity measurements by video analysis of dye tracer in a macro-rough channel
}

\author{
T Ghilardi, M J Franca and A J Schleiss \\ Laboratory of Hydraulic Constructions (LCH), Ecole Polytechnique Fédérale de Lausanne (EPFL), \\ Station 18, 1015 Lausanne, Switzerland \\ E-mail: tamara.ghilardi@epfl.ch
}

Received 26 June 2013, revised 1 November 2013

Accepted for publication 2 January 2014

Published 5 February 2014

\begin{abstract}
Steep mountain rivers have hydraulic and morphodynamic characteristics that hinder velocity measurements. The high spatial variability of hydraulic parameters, such as water depth (WD), river width and flow velocity, makes the choice of a representative cross-section to measure the velocity in detail challenging. Additionally, sediment transport and rapidly changing bed morphology exclude the utilization of standard and often intrusive velocity measurement techniques. The limited technical choices are further reduced in the presence of macro-roughness elements, such as large, relatively immobile boulders. Tracer tracking techniques are among the few reliable methods that can be used under these conditions to evaluate the mean flow velocity. However, most tracer tracking techniques calculate bulk flow velocities between two or more fixed cross-sections. In the presence of intense sediment transport resulting in an important temporal variability of the bed morphology, dead water zones may appear in the few selected measurement sections. Thus a technique based on the analysis of an entire channel reach is needed in this study. A dye tracer measurement technique in which a single camcorder visualizes a long flume reach is described and developed. This allows us to overcome the problem of the presence of dead water zones. To validate this video analysis technique, velocity measurements were carried out on a laboratory flume simulating a torrent, with a relatively gentle slope of $1.97 \%$ and without sediment transport, using several commonly used velocity measurement instruments. In the absence of boulders, salt injections, WD and ultrasonic velocity profiler measurements were carried out, along with dye injection technique. When boulders were present, dye tracer technique was validated only by comparison with salt tracer. Several video analysis techniques used to infer velocities were developed and compared, showing that dye tracking is a valid technique for bulk velocity measurements. RGB Euclidean distance was identified as being the best measure of the average flow velocity.
\end{abstract}

Keywords: bulk flow velocity, macro-rough channel, dye tracer tracking

(Some figures may appear in colour only in the online journal)

\section{Introduction}

Mountain rivers occupy a significant part of world catchments. Although they control sediment supply to lowland rivers, relatively few studies have been carried out on these torrents. They are characterized by longitudinal slopes ranging from
$0.1 \%$ to $20 \%$ (Papanicolaou et al 2004) and by a wide grain size distribution composed of fine mobile sediments and large, relatively immobile, boulders (Rickenmann 2001, Yager et al 2007), which can be arranged randomly or in rows (Pagliara and Chiavaccini 2006). In torrents, the water depth (WD) is small in comparison to the roughness elements, and 
the sediment transport can be intense. Bed morphology and hydraulic parameters, such as WD and flow velocity, have high spatial variability, and in the presence of sediment transport, high temporal variability can also be observed in the abovementioned parameters (Recking et al 2009). Challenges in measuring hydraulic parameters under these conditions are found not only in the field (Calkins and Dunne 1970, Church and Kellerhals 1970) but also in laboratory experiments (Recking 2006, Pagliara 2007). High spatial variability of the channel morphology does not allow sampling on a regular grid, while the high temporal variability does not allow the installation of fixed systems. The presence of macro-roughness elements hinders the use of methods sampling a large flow surface, the small WD excludes most intrusive techniques since these would disturb the flow, and the presence of intense sediment transport excludes the use of fragile instruments. Thus most of the existing velocity measurement techniques are not appropriate, and selecting one or several representative cross-sections (i.e. average or typical cross-sections) to estimate average velocities is challenging in macro-rough mountain torrents (Calkins and Dunne 1970). Due to the spatiotemporal variability, hydraulic parameters such as the WD and the average flow velocity are often not measured but estimated indirectly using empirical relationships, for example resistance equations (Yager et al 2007, Recking et al 2009, Pagliara et al 2010, Heyman et al 2013).

The present paper focuses on bulk flow velocity measurement techniques in an experimental flume. Several difficulties in performing velocity measurements can be identified for our sediment transport flume experiments (Ghilardi and Schleiss 2012): small average flow depth (between 0.027 and $0.053 \mathrm{~m}$ ); high variability of WD both in space and time (up to $0.1 \mathrm{~m}$ ); mobile and rapidly changing bed; intense sediment transport; roughness elements often protruding from the water (in our particular case, due to the presence of boulders); small flume width (here, $0.25 \mathrm{~m}$ ). One technique, based on video analysis of dye tracer over an entire flume reach, proved to be adequate for estimating channel flow velocities.

In section 2, a review of some existing velocity measurement techniques is presented, and their application to the hydraulic conditions of steep rough channels is described. In section 3 , the experimental facility is described. Section 4 presents the procedure of the dye tracking technique leading to the estimation of the bulk flow velocities. Section 5 compares the dye tracer technique and data treatment to other velocity measurement methods for validation purposes. Salt and dye tracer tracking measurements are the only available methods that are applicable in the presence of boulders. In the absence of boulders, direct ultrasonic velocity profiles, velocity measurements and mean velocities inferred from WD measurements are also used for comparison. In section 6 the main conclusions are given.

\section{Review of main velocity measurement techniques}

Most velocity estimation techniques yield local information about the flow conditions. These methods require that one or more representative cross-sections are identified. The data obtained for the cross-sections are then averaged to estimate the average bulk flow velocity. Techniques that are commonly used to measure velocity in open-channel flows include: water depth (WD) measurements; micro-propeller vertical profiling; acoustic Doppler velocimeter (ADV); ultrasonic velocity profiles (UVP); acoustic Doppler velocity profiles (ADVP); acoustic Doppler current profilers (ADCP); hot wire; laser Doppler anemometry (LDA); electromagnetic current meters (EMC); Pitot probes; particle image velocimetry (PIV) and particle tracking velocimetry (PTV); tracer tracking methods, with various types of tracers (salt and dyes).

WD measurements (using point-gauges, ultrasonic distance meters and other instruments) and back-calculation of flow velocity seems to be a simple technique for determining average flow velocities when the discharge is known. However, as mentioned before, representative cross-sections are difficult to identify and other challenges need to be tackled. It is difficult to determine the base level (bed level) from which the WD has to be measured, primarily because of the high relative roughness encountered in mountain rivers. The uncertainty of the WD measurement is directly linked to the ratio between the WD and the roughness height (Rickenmann 1990, Recking 2006). Thus large errors may occur in WD measurements in torrents, since the elevation of the bed changes abruptly over short distances. The bed level is even more difficult to determine in the presence of intense bedload, because of the existence of a moving layer and rapid changes in the bed configuration. Moreover, the water surface is highly irregular, thus making its unambiguous measurement difficult.

Micro-propeller vertical profiling (full- and partial-depth (Church and Kellerhals 1970)) are easy and precise ways to measure the mean velocities of flows with simple geometries in clear-water prismatic open-channels. In the flows targeted in the present research, however, several disadvantages of this method exist, including the sensitivity of the instrumentation blades to impact with sediments transported by the flow and the intrusiveness of the method, which causes local erosion when measuring velocities near a mobile bed.

Techniques based on the Doppler shift frequency of the echoes reflected by small suspended particles (seeding) comprise: ADV, UVP, 3D ADVP and ADCP.

ADV, composed of one central emitter and three (or four) sound receivers, allows point measurements of the three components of the flow velocity. It has been widely used for a long time in laboratory (Kraus et al 1994) and field (Wilcox and Wohl 2007) studies of open-channel flows. ADVs need to be immersed in the water, thus are intrusive, and require space to accommodate the probes and the near field needed between the emitter and the measuring point. In shallow flows with restricted space for the measurements, this technique is limited. Furthermore, when the aim is to obtain bulk-average velocities, ADV requires a large amount of measuring points.

UVP (Amini et al 2009) measure instantaneous velocity $1 \mathrm{D}$ profiles along a beam axis. Several beams can be used to obtain velocity profiles at a single cross-section and an average cross-section velocity can then be calculated. Bathymetry uncertainties for UVP measurements are normally of the size 
of one measuring gate. Thus this is not relevant in the present case for the calculation of vertical averaged velocities. UVP transducers need to be partially immersed in the water; thus UVP measurement is an intrusive technique. In the present case, with widely varying water levels and bed morphology, the use of UVP with a regular sampling grid for the cross-sections is not possible. Moreover, the size of mobile sediments is not negligible with respect to the WD, and the signal echoed by gravel interferes with the backscattered signal.

ADVP, developed at the Ecole Polytechnique Fédérale de Lausanne (EPFL) (Franca and Lemmin 2006), allow full-depth quasi-instantaneous 3D velocity profiling and are suitable for use both in the field (Franca et al 2008) and in the laboratory (Blanckaert and De Vriend 2004, Leite Ribeiro et al 2012, Dugué et al 2013). ADVP are intrusive, and while this influence is negligible for slow flow, at high flow velocities such as those considered in this study, ADVP change the flow characteristics and influence flow velocities. The presence of macro-rough elements and gravel bars precludes the use of ADVP because they require considerable free space.

ADCP, constituted typically of a central body where diverging transducers working simultaneously as emitters and receptors are installed, are commonly used for large-scale studies. They are used for estimating large features of flows in lakes (Lorke and Wüest 2005) and rivers (Le Coz et al 2008). The dimensions of ADCP instrumentation and the weight do not allow easy and fine displacement of the instrumentation in shallow flows with such singularities and obstacles as bed forms and large boulders.

Techniques commonly used to measure flow velocities in fluid mechanics, such as hot wire anemometry (cf Hinze (1975) for details) and LDA (cf Nezu and Nakagawa (1993) for details), are not adequate in the case of intense bedload transport and spatial variability of the channel bed. Furthermore, the apparatus is not easily movable, which is important when local conditions change so abruptly in space such as the herein treated channel flows. With the presence of boulders and bed forms, the installation of such equipment in a flume is not easy. Regarding LDA, hidden (shadow) areas of the flow hinder the penetration of the laser light.

Electromagnetic current meters use the Faraday principle of electromagnetic induction, stating that the voltage produced by water moving in a magnetic field is proportional to the velocity of the water (MacVicar et al 2007). ECM is used in laboratory and field research (Roy et al 2004), for 2D velocity measurements. This instrumentation is robust, but too intrusive and thus disturbing to the flow (Voulgaris and Trowbridge 1998).

Pitot probes (USBR 1980), commonly used for field measurements, are also too intrusive. Furthermore, the risk of damage is high when used in shallow flow with intense sediment transport.

PIV and PTV, particularly large-scale particle image velocimetry (LSPIV), are techniques for measuring velocity fields based on image analysis, i.e. tracking light particles transported by the flow. PIV uses a laser to illuminate particle transport by a thin layer in the flow (Raffel et al 1998, Pokrajac et al 2007), while LSPIV uses only light particles transported on the water surface (Fujita et al 1998, van Prooijen and Uijttewaal 2002, Jodeau et al 2008, Muste et al 2008, Kantoush et al 2011, Mattioli et al 2012). The light particles on the surface are representative of the surface flow velocity and recirculation cells with signatures at the free surface (van Prooijen and Uijttewaal 2002) and can be applied in shallow water, where the horizontal velocity is predominant and greatly exceeds the vertical velocity. These applications need extremely controlled light conditions and special equipment, and in the presence of intense sediment transport, they present problems in the identification of tracking particles.

If the reach average bulk velocity has to be known, as was the case in our research project, tracer tracking techniques are sufficient (Ghilardi and Schleiss 2011, 2012). These techniques are applicable in both the field (Calkins and Dunne 1970, Church and Kellerhals 1970) and the laboratory (Cao 1985, Rickenmann 1990, Weichert 2005, Recking et al 2008). Four types of tracer exist: salt, dye, other traceable chemical compounds and radioisotopes (Church and Kellerhals 1970). The first two tracer types are the most widely used. The tracer travel time can be calculated either between the injection point and the measurement point (Calkins and Dunne 1970) or between two or more sampling positions (Rickenmann 1990, Recking et al 2008). The latter method is generally used for laboratory experiments.

In salt tracer velocity measurement, a slug of salt solution is injected into the water, and the water conductivity increases due to the passage of the salt cloud. This change in conductivity can be recorded at one or more measurement cross-sections by means of electrode couples, providing conductivity-time curves. These electrode couples are often formed by two vertical metal strips attached to opposite walls of the channel at a selected cross-section (Smart and Jäggi 1983, Weichert 2005). In the case of high temporal bed variability (vertical fluctuations), the electrodes need to be long enough to accommodate the changes in the bed level. The fluid velocity can be calculated as the distance between two cross-sections divided by the travel time of the tracer cloud between them. The starting point of conductivity increase is generally clearly defined. The identification of the end point is often difficult because the tail of the curve can be relatively long (Day 1976, Rickenmann 1990). This is also the case when working with dye as a tracer. Water conductivity can also be measured by conductivity-meter probes, which measure the change in conductivity between two electrodes placed only a few millimetres apart from each other. Since intrusive and local, the choice of a representative point for the measurement is needed. In our study, we used vertical metal strips attached to the flume walls to carry out conductivity measurements, in order to obtain average values over the cross-section.

Video camera-based techniques are often used in hydraulics research to estimate flow velocities (Le Coz et al 2010, Mattioli et al 2012) and concentration fields (Thomas and Marino 2012, Nogueira et al 2013). Dye tracer velocities can be estimated by means of video analysis. Recking et al (2008) described the introduction of a slug of colorant in a flume and the analysis of the passage of the cloud between two positions in the flume using two video cameras (recording 
at 20 frames per second) placed $4 \mathrm{~m}$ apart from each other at the flume surface. Only two cross-sections were thus analysed. The two camcorders must be perfectly synchronized for the travel time to be calculated correctly. Recking (2006) reported that for highly turbulent flow ( $\operatorname{Re}>6000)$, no infiltration of the colorant in the bed was observed; thus, no delay in the tracer release was introduced. He emphasized that for steep slopes $(9 \%)$ and small relative WDs, the signal can be quite noisy due to the rapid changes in light conditions induced by the fluctuating water surface. Nevertheless, the shape of the concentration curve remains the same. The video was analysed in grey scale, and the colorant plume was identified by a peak in grey scales (the image becomes darker). The peak velocity was used by Recking to estimate the bulk velocity.

Tracer tracking measurements over time at one fixed position provide three types of information: the initial rise in concentration, the peak concentration and the centre of mass of the tracer cloud. According to Calkins and Dunne (1970), the initial rise in concentration is a measure of the maximum velocity through the channel reach. The peak in concentration is commonly used to obtain the travel time and sometimes to estimate the bulk flow velocity. Calkins and Dunne (1970) and Church and Kellerhals (1970) claim that the time delay of the centroid of the concentration curve between two points represents the mean residence time of the tracer in the reach between the aforementioned points and thus can be used to estimate the mean velocity in the reach. Researchers primarily use centroid velocities to estimate bulk flow velocities (Church and Kellerhals 1970, Davies and Jäggi 1981, Smart and Jäggi 1983, Rickenmann 1990, Weichert 2005), although some researchers use the peak tracer concentration (Cao 1985, Recking 2006, Recking et al 2008). Cao (1985) compared the velocities estimated using the peak and the centre of mass of the salt solution and those estimated from WD measurement and found that velocities estimated using the peak of the conductivity travel time were closer to those estimated from WD measurement. He attributes this outcome to the presence of 'dead zones', characterized by small longitudinal velocities, that result in slow release of the tracer after the passage of the main flow and the formation of long tails in the conductivity curves (Cao 1985). According to Day (1976) and Church and Kellerhals (1970), gross errors in salt tracking can occur if the electrode is placed in a zone with no longitudinal velocity component (a dead zone) in the stream.

The main difficulty with the salt and dye tracer techniques is the choice of representative cross-sections for the measurements, as discussed in the introduction. For instance, if the measurement is carried out in a section where a dead zone is present, the final result could be strongly affected. A new method for analysing a whole reach at once is thus presented in this study.

Table 1 summarizes a critical assessment stating the main advantages and drawbacks of the aforementioned techniques for conditions where channel bed morphology is quite heterogeneous, the roughness elements have low submergence and intense bedload occurs. The intrusiveness criterion is relevant for small flow depth. Intrusive methods would greatly influence the flow conditions and the bed morphology. The sediment transport criterion addresses both the bedload and the suspended load. It indicates if the presence of sediment transport would be a problem for the integrity of the technique and for the field of view of this (i.e. LDA). The number of measures criterion refers to the sampling grid density necessary to obtain bulk-average velocities, which may be time consuming and difficult to position in shallow flows. The spatiotemporal variability, including the presence of protruding boulders, is a problem for all the techniques requiring a regular sampling grid. The presence of dead water zones complicates the choice of a representative cross-section. This is especially the case for tracer tracking between two fixed sections, since the position of dead water zones varies in space and time in a way that measurement positions are influenced. Finally, the presence of air in the flow, which may be relevant immediately downstream of boulders, would be a main drawback for some of the measurement techniques.

\section{Experimental details}

The velocity measurement technique presented herein was developed within the framework of a research project focused on analysing the impact that randomly distributed relatively immobile boulders have on sediment transport in steepslope rivers. This research was carried out using mobile bed laboratory experiments conducted using a tilting flume $8 \mathrm{~m}$ long (with a usable length of $7 \mathrm{~m}$ ) and $0.25 \mathrm{~m}$ wide (figure 1) at the Laboratory of Hydraulic Constructions ( $\mathrm{LCH}$ ) of the Ecole Polytechnique Fédérale de Lausanne (EPFL) (Ghilardi and Schleiss 2011, 2012).

For the comparison with the standard velocity measurement techniques, the flume slope was set to $\alpha=$ $1.97 \%$ to produce a high WD but no sediment transport. Water discharge, fed constantly by a closed pumping system, was measured using an electromagnetic flow meter $\left( \pm 0.01 \mathrm{l} \mathrm{s}^{-1}\right)$. A plane bed was prepared with sediments with the following grain size distribution characteristics: $d_{m}=d_{65}=11.9 \mathrm{~mm}$, $d_{30}=7.1 \mathrm{~mm}$, and $d_{90}=19 \mathrm{~mm}$, where $d_{m}$ is the mean grain size, corresponding to $d_{65}$, and $d_{x}$ is the grain size diameter at which $x \%$ by weight of the sediments are smaller. During the experiments, no sediment transport occurred; thus, no bed forms were observed.

In the case of a plane bed test without boulders, flow velocities were measured by four techniques for three different discharge rates: 5.0, 7.25 and $9.51 \mathrm{~s}^{-1}$. This range was chosen to yield a sufficiently high WD for UVP measurement $(37 \mathrm{~mm}$ on average for $Q=5.0 \mathrm{l} \mathrm{s}^{-1}$ ) on the one hand and avoid local scouring downstream of boulders and sediment transport (limiting the discharge to $Q=9.51 \mathrm{~s}^{-1}$ ) on the other hand. UVP and WD measurements yielded estimates of the flow velocity for a given cross-section. For both methods, 17 cross-sections, spaced $0.1 \mathrm{~m}$ apart longitudinally, were gauged at distances between 2.55 and $4.25 \mathrm{~m}$ from the flume inlet (see figure 1). The water and bed levels were measured at 12 equally spaced locations - thus, every $0.02 \mathrm{~m}$-across every section using a point-gauge. Three $4 \mathrm{MHz}$ UVP probes were placed in the cross-section, at the middle, first quarter and third quarter of 


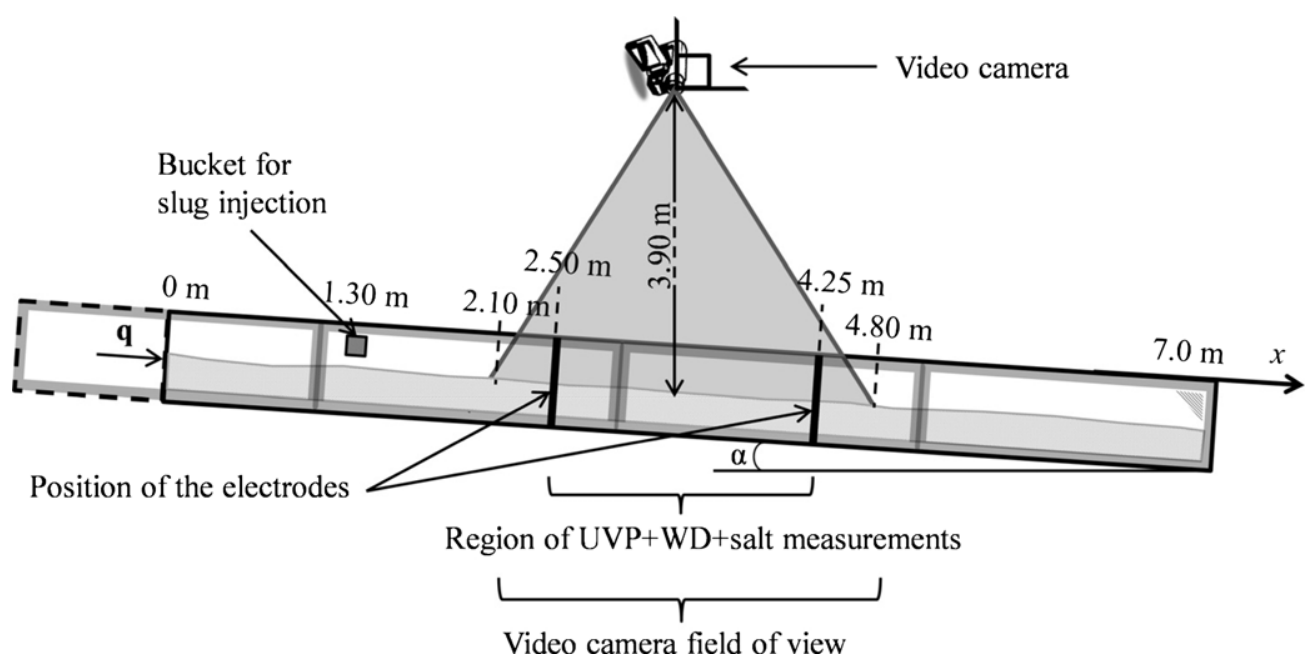

Figure 1. Sketch of the flume with the measurement zones.

the flume width $(0.25 \mathrm{~m})$, at an angle of $20^{\circ}$ with the vertical. The depth-averaged velocity profiles were used to calculate the bulk average cross-sectional velocity.

For the salt velocity measurements, two pairs of electrodes were placed on the flume wall, $1.75 \mathrm{~m}$ apart from each other in the streamwise direction (at 2.50 and $4.25 \mathrm{~m}$ from the flume inlet), as shown in figure 1, to measure the conductivity of the water.

For the fourth velocity measurement technique, developed in the present research, a single video camera was used (see figure 1). The camera was positioned horizontally above the flume, approximately $3.9 \mathrm{~m}$ above the water surface. The area within the camera field of view was slightly larger than the flume domain measured by the other systems, between 2.10 and $4.80 \mathrm{~m}$ from the inlet of the flume. Spotlights on the laboratory ceiling were systematically lit during the experiments, but ambient light from outside the laboratory was also present. More details on this technique are given in section 4.

Slug injections of dye (potassium permanganate, which has a dark violet colour) and salt were conducted at the same time. A mixture of water, salt and dye was injected in the flume instantaneously through the whole flume width, using a tilting bucket with a volume of approximately $200 \mathrm{ml}$, located $1.3 \mathrm{~m}$ from the inlet. The amount of dye and salt added is not relevant to the velocity measurements because the only requirements are that the salt peak is well defined and that the dye contrast is sufficient to be visible in the videotapes. For each tested discharge rate, the procedure was repeated five times, and the average velocity value was calculated. Visual observations of the colorant injection confirmed good and rapid vertical mixing. The problem of slow transverse mixing was solved by injecting the tracer simultaneously across the whole width of the flume. In the longitudinal direction, the velocity of the colorant is equivalent to the velocity of the flow after the advective zone (where an equilibrium is established between the effects of velocity shear and turbulent diffusion (Rutherford 1994)). Thus the colorant injection point should be selected carefully relatively to the field of measurements. In our case, the field of view of the camera was downstream of the advective zone. This is confirmed by the validation of the velocity measurement made with other techniques further in this text. Since a large flume reach $\left(0.25 \times 2.70 \mathrm{~m}^{2}\right)$ is globally assessed by our technique, dead zones do not present a concern.

When channel velocity measurements were carried out with boulders present, only tracer techniques (salt and dye) were used. WD measurements were not feasible because of the presence of hydraulic jumps and rapid local variations in the water surface. UVP could not be used for the same reasons and because of the difficulty of sampling with a regular grid in the presence of boulders. Tests were conducted for two dimensionless distances between boulders, $\lambda / D=2$ and $\lambda / D=3$, where $\lambda$ is the average distance between boulders and $D$ is the boulder diameter. Boulders with $D=0.1 \mathrm{~m}$ were used in these tests. Bed sediments covered approximately half of the boulders' height.

\section{Dye tracking velocity measurement technique}

\subsection{Video camera setup}

A tracer-based velocity measuring technique using one video camera (SONY DCR-HC48E, 24 frames per second, $576 \times 720$ pixels) covering a wide domain of the channel $\left(0.675 \mathrm{~m}^{2}\right.$, as described in section 3$)$ is herein described and compared with other velocimetry methods. This technique differs from other dye-tracer based methods described in the literature, in which two cameras are used and the velocity is estimated by analysing correlated concentration time signals acquired simultaneously at the two camera positions (Recking et al 2008). That is, the measurement technique developed in this study takes into account a whole channel reach, rather than only what happens on average between two cross-sections, as do standard salt tracking methods and the dye method presented by Recking et al (2008). This allows avoiding the problem of dead water zones, which can develop during mobile bed experiments at the position where the measurement equipment (video camera or electrodes, according to the method) is initially placed. 


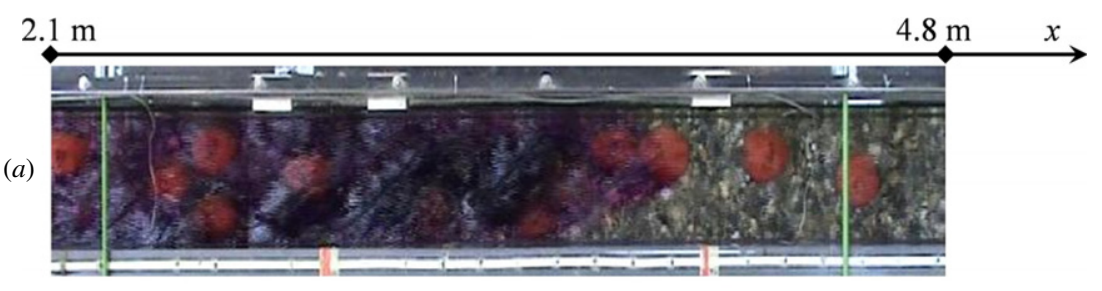

(b)
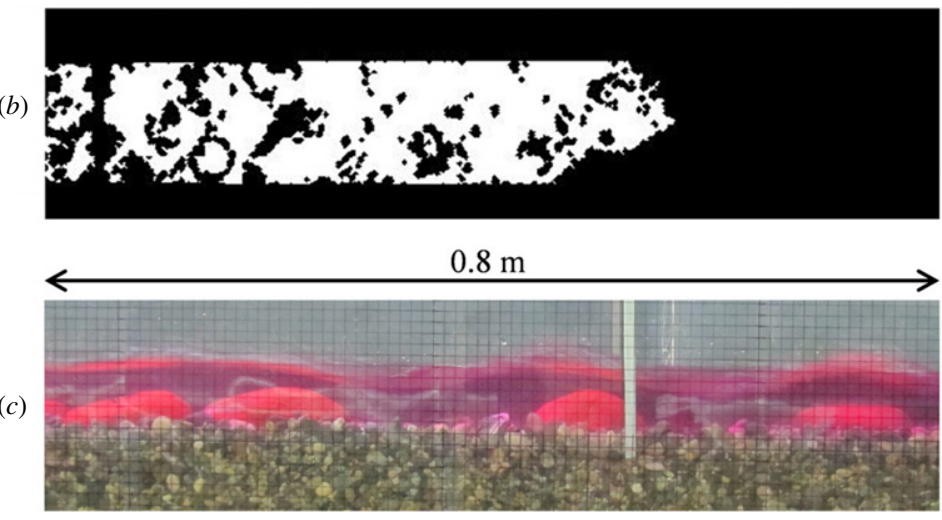

Figure 2. (a) An example of a video frame with colorant. (b) The white pixels are those where colorant was detected in the video analysis, for the same frame shown in $(a)$. (c) Image of a side view of the flume $(0.8 \mathrm{~m}$ reach) with colorant. Boulders are coloured in red and the dye is purple.

Reference bars (see figure 2(a)) placed transversally on top of the flume permit adequate longitudinal image scaling, which compensates for the distortion due to the inclination and the position of the flume with respect to the camera. The lenses distortion has not been considered, because a longitudinal correction is already done based on the position of the reference bars with respect to the centre of the image. The latter has a known position along the flume. The camera is aligned with the flume axis and the flow occurs from left to right in the video, thus every vertical column of pixels in a frame corresponds to a cross-section in the flume. This means that approximately 720 cross-sections are measured in a stretch of approximately $2.7 \mathrm{~m}$, yielding a cross-section every $4 \mathrm{~mm}$.

\subsection{Video analysis and velocity estimation}

Recorded video images can be treated in various colour spaces to identify the colorant and calculate an intensity curve with respect to time: greyscale (as used by Recking et al (2008)), RGB (red/green/blue), CYMK (cyan/yellow/magenta/black), HSL levels (hue/saturation/luminosity), single colours, or a combination of these options.

Greyscale and RGB-scale images (obtained through analysis of the RGB Euclidean distance, $\mathrm{ED}_{\mathrm{RGB}}$, as described below) were applied and compared in the present study. Two types of greyscale analysis were used: grey levels (GL) method and cross-section grey levels (CSGL) method.

To determine the dye concentration over time, using the GL method, the image is converted into grey scale, and then only the value of every pixel where colorant is found is taken into account. An average concentration is calculated over time (frames) for every cross-section (column).

In the CSGL method, the image is also converted into a greyscale image. However, unlike in the GL method, the whole flume width, including the area where colorant is not present, is taken into account in calculating the average grey-level value, according to the procedure used by Recking et al (2008). This approach was adopted for all of the frames and was applied to approximately 720 cross-sections. In this respect, the approach taken differed from the two-section analysis approach used by Recking et al (2008). A data analysis is needed in order to identify the part of the dye intensity curve indicating the presence of colorant (greyscale levels 10\% darker than the base image), especially to identify the end of the cloud, given the long tail of the curve (cf section 1).

For the RGB analysis, a base RGB image that serves as reference is obtained by averaging ten frames before the colorant arrival. Every pixel thus has an average base RGB value. In the subsequent frames, when colorant is identified in a pixel, the RGB Euclidean distance ( $E D_{\mathrm{RGB}}$, equation (1)) is calculated as follows:

$\operatorname{ED}_{\mathrm{RGB}}(t)=\sqrt{\left(R(t)-R_{b}\right)^{2}+\left(G(t)-G_{b}\right)^{2}+\left(B(t)-B_{b}\right)^{2}}$,

where the index $b$ indicates the RGB value of the base image and $t$ denotes the time. Only pixels where the dye tracer has been identified are used.

In order to detect the presence of colorant, several colour maps, such as the RGB colours, the grey-level values and the HSV values, were analysed and compared visually with the video images. Then, a criterion based on a combination of minimum and maximum values of these colour scales was established to indicate the presence of colorant. This thorough procedure is made for each experimental configuration (same light conditions and hydraulic conditions, for the same camera position), and assumed valid through the entire duration of the experiment.

For the calculation of the colorant concentration in the images, a base image without colorant and the image with colorant were compared. In turbulent flows, the velocity 


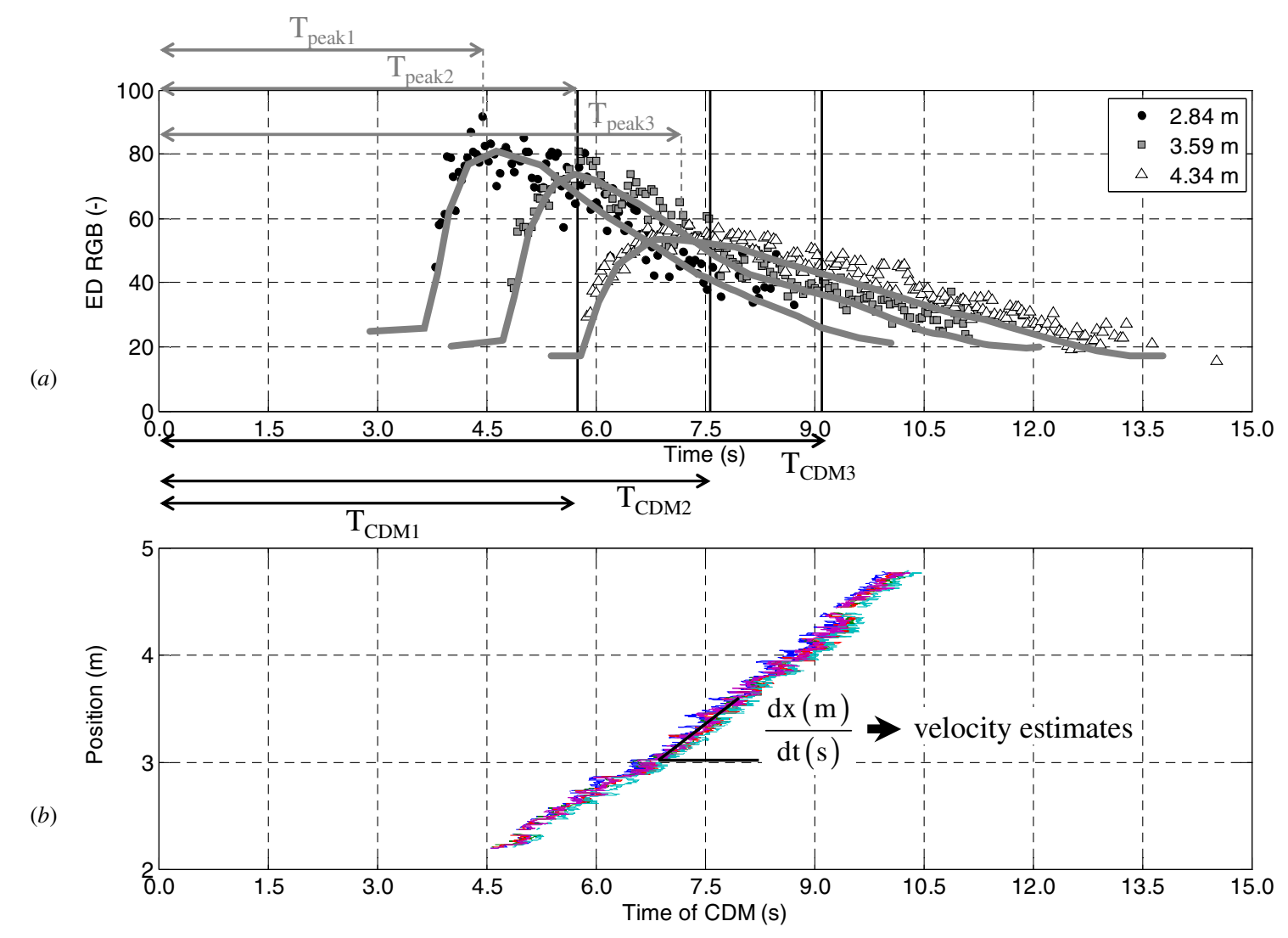

Figure 3. (a) An example of RGB Euclidean distance $\left(\mathrm{ED}_{\mathrm{RGB}}\right)$ time evolution for cross-sections at $2.84,3.59$ and $4.34 \mathrm{~m}$ (for colorant injection without boulders at a discharge rate of $\left.5.01 \mathrm{~s}^{-1}\right)$. The times of centroids $\left(T_{\mathrm{CDM}}\right)$ and of peaks $\left(T_{\text {peak }}\right)$ are identified on the graph. A sketch of the concentration curve is given for each cross-section. (b) Position of the centroid CDM over time, estimated for each longitudinal position for the five colorant injections.

Table 1. Comparison of the advantages $(\sqrt{ })$ and drawbacks $(x)$ of the mentioned techniques to estimate bulk flow velocity in open-channel flows. In section $5 \mathrm{WD}, \mathrm{UVP}$ and salt (metal strips) are compared with the technique herein developed: dye (1 reach).

\begin{tabular}{lllllll}
\hline Method & \multicolumn{5}{c}{ Advantages $(\sqrt{ }) /$ Drawbacks (x) } \\
\cline { 2 - 7 } & Intrusiveness & $\begin{array}{l}\text { Sediment } \\
\text { transport }\end{array}$ & $\begin{array}{l}\text { Number of } \\
\text { measures }\end{array}$ & $\begin{array}{l}\text { Spatiotemporal } \\
\text { variability }\end{array}$ & $\begin{array}{l}\text { Dead water } \\
\text { zones }\end{array}$ & Aeration \\
\hline Water depth & $\sqrt{ }$ & $\mathrm{x}$ & $\sqrt{ }$ & $\mathrm{x}$ & $\sqrt{ }$ & $\sqrt{ }$ \\
Micro-propeller & $\mathrm{x}$ & $\mathrm{x}$ & $\mathrm{x}$ & $\mathrm{x}$ & $\mathrm{x}$ & $\mathrm{x}$ \\
ADV & $\mathrm{x}$ & $\mathrm{x}$ & $\mathrm{x}$ & $\mathrm{x}$ & $\mathrm{x}$ & $\mathrm{x}$ \\
UVP & $\mathrm{x}$ & $\mathrm{x}$ & $\mathrm{x}$ & $\mathrm{x}$ & $\mathrm{x}$ & $\mathrm{x}$ \\
ADVP & $\mathrm{x}$ & $\mathrm{x}$ & $\mathrm{x}$ & $\mathrm{x}$ & $\sqrt{ }$ & $\mathrm{x}$ \\
ADCP & $\mathrm{x}$ & $\mathrm{x}$ & $\mathrm{x}$ & $\mathrm{x}$ & $\mathrm{x}$ & $\mathrm{x}$ \\
Hot wire & $\mathrm{x}$ & $\mathrm{x}$ & $\mathrm{x}$ & $\mathrm{x}$ & $\sqrt{ }$ & $\mathrm{x}$ \\
LDA & $\sqrt{ }$ & $\mathrm{x}$ & $\mathrm{x}$ & $\mathrm{x}$ & $\mathrm{V}$ & $\mathrm{x}$ \\
ECM & $\mathrm{x}$ & $\mathrm{x}$ & $\mathrm{x}$ & $\mathrm{x}$ & $\mathrm{x}$ & $\mathrm{x}$ \\
Pitot probe & $\mathrm{x}$ & $\mathrm{x}$ & $\mathrm{x}$ & $\mathrm{x}$ & $\mathrm{x}$ & $\sqrt{ }$ \\
PIV/LSPIV & $\sqrt{ }$ & $\sqrt{ }$ & $\sqrt{ }$ & $\sqrt{ }$ & $\mathrm{x}$ & $\sqrt{ }$ \\
Salt (probe) & $\mathrm{x}$ & $\sqrt{ }$ & $\mathrm{x}$ & $\mathrm{x}$ & $\mathrm{x}$ & $\sqrt{ }$ \\
Salt (metal strips) & $\sqrt{ }$ & $\sqrt{ }$ & $\sqrt{ }$ & $\sqrt{ }$ & $\sqrt{ }$ \\
Dye (2 sections) & $\sqrt{ }$ & $\sqrt{ }$ & $\sqrt{ }$ & $\sqrt{ }$ & $\sqrt{ }$ & $\sqrt{ }$ \\
Dye (1 reach) & $\sqrt{ }$ & $\sqrt{ }$ & $\sqrt{ }$ & $\sqrt{ }$ &
\end{tabular}

distribution is almost uniform within the flow depth, thus detection of the dye intensity may be considered representative of the total colorant concentration in the vertical layer and not only of the flow surface.

Table 2 summarizes the characteristics and the differences between the aforementioned video analysis methods.
Figure 2(a) shows a frame with colorant in the presence of boulders, and figure 2(c) illustrates the coloured flow with a side view of the flume. Figure $2(b)$ shows in white the pixels where colorant has been detected during the video analysis. In some regions, the colorant could not be identified because of the reflection of light on the water surface. However, this 
Table 2. Comparison of the video analysis techniques used.

\begin{tabular}{llll}
\hline Video analysis method & Colour scale & Colour intensity & Pixels used \\
\hline ED $_{\text {RGB }}$ & RGB & Equation (1) & Only those with dye \\
GL & Grey scale & Grey level & Only those with dye \\
CSGL & Grey scale & Grey level & Entire flume width \\
\hline
\end{tabular}

Table 3. Results of mean velocity $\left(\mathrm{m} \mathrm{s}^{-1}\right)$ measurements for the three techniques WD, UVP and salt (peak $S_{\text {peak }}$ and centroid $S_{\mathrm{CDM}}$ ) and the centroid and peak velocity for the colorant-based video analysis technique: $\mathrm{ED}_{\mathrm{RGB}}$ (RGB Euclidean distance), GL (grey levels) and CSGL (cross-section grey levels).

\begin{tabular}{|c|c|c|c|c|c|}
\hline & \multicolumn{3}{|c|}{$Q\left(1 \mathrm{~s}^{-1}\right)$} \\
\hline & & & 5.00 & 0.66 & 9.50 \\
\hline \multirow[t]{10}{*}{ Without boulders } & & WD & 0.53 & 0.59 & 0.72 \\
\hline & & UVP & 0.47 & 0.73 & 0.69 \\
\hline & & $S_{\mathrm{CDM}}$ & 0.48 & 0.52 & 0.66 \\
\hline & & $S_{\text {peak }}$ & 0.52 & 0.72 & 0.74 \\
\hline & & $\mathrm{ED}_{\mathrm{RGB}}, \mathrm{CDM}$ & 0.46 & 0.51 & 0.65 \\
\hline & & $\mathrm{ED}_{\mathrm{RGB}}$, peak & 0.51 & 0.74 & 0.76 \\
\hline & & $\mathrm{GL}_{\mathrm{CDM}}$ & 0.41 & 0.53 & 0.56 \\
\hline & & $\mathrm{GL}_{\text {peak }}$ & 0.51 & 0.72 & 0.76 \\
\hline & & $\mathrm{CSGL}_{\mathrm{CDM}}$ & 0.48 & 0.56 & 0.61 \\
\hline & & $\mathrm{CSGL}_{\text {peak }}$ & 0.52 & 0.72 & 0.74 \\
\hline \multirow[t]{16}{*}{ With boulders } & $\lambda / D=2$ & $S_{\mathrm{CDM}}$ & 0.49 & 0.50 & 0.62 \\
\hline & & $S_{\text {peak }}$ & 0.72 & 0.63 & 0.66 \\
\hline & & $\mathrm{ED}_{\mathrm{RGB}}, \mathrm{CDM}$ & 0.54 & 0.46 & 0.59 \\
\hline & & $\mathrm{ED}_{\mathrm{RGB}}$, peak & 0.72 & 0.61 & 0.73 \\
\hline & & $\mathrm{GL}_{\mathrm{CDM}}$ & 0.28 & 0.40 & 0.52 \\
\hline & & $\mathrm{GL}_{\text {peak }}$ & 0.44 & 0.61 & 0.72 \\
\hline & & $\mathrm{CSGL}_{\mathrm{CDM}}$ & 0.36 & 0.43 & 0.51 \\
\hline & & $\mathrm{CSGL}_{\text {peak }}$ & 0.45 & 0.61 & 0.74 \\
\hline & $\lambda / D=3$ & $S_{\mathrm{CDM}}$ & 0.32 & 0.44 & 0.53 \\
\hline & & $S_{\text {peak }}$ & 0.34 & 0.65 & 0.72 \\
\hline & & $\mathrm{ED}_{\mathrm{RGB}}, \mathrm{CDM}$ & 0.32 & 0.43 & 0.56 \\
\hline & & $\mathrm{ED}_{\mathrm{RGB}}$, peak & 0.47 & 0.64 & 0.72 \\
\hline & & $\mathrm{GL}_{\mathrm{CDM}}$ & 0.27 & 0.37 & 0.49 \\
\hline & & $\mathrm{GL}_{\text {peak }}$ & 0.42 & 0.62 & 0.72 \\
\hline & & $\mathrm{CSGL}_{\mathrm{CDM}}$ & 0.38 & 0.43 & 0.54 \\
\hline & & CSGL $_{\text {peak }}$ & 0.39 & 0.60 & 0.72 \\
\hline
\end{tabular}

corresponds to an average error in colorant concentration below $10 \%$ on a cross-section.

For every cross-section, the average colorant concentration is calculated as a function of time. Time series were obtained for all of the video analysis techniques mentioned, namely, $\mathrm{ED}_{\mathrm{RGB}}$, GL and CSGL. As mentioned previously, methods for estimating flow velocity from concentration time series use as a reference either the peak value (estimating the time between peaks measured at two different positions) or the time corresponding to the centroid of the curve (estimating the time between centroids measured at two different positions) (Calkins and Dunne 1970). Both methods are applicable to our technique and are demonstrated and discussed herein.

The position of the centroid of the curve over time is calculated at every cross-section, and the time corresponding to the peak is registered. Figure 3(a) presents a typical colorant concentration evolution over time, exemplified for $\mathrm{ED}_{\mathrm{RGB}}$, for three different longitudinal positions along the channel. The concentration curve is also sketched in figure 3(a). From one position in the flume to another, there is a shift in time and a decrease in the maximum concentration (the maximum $\mathrm{ED}_{\mathrm{RGB}}$ value). For every curve, a $T_{\text {peak }}$ can be identified. Examining the curve corresponding to the cross-section at $3.59 \mathrm{~m}$, one can see that defining $T_{\text {peak }}$ may be challenging due to the scatter of the points. For every concentration curve, a centroid is calculated, producing a corresponding time $T_{\mathrm{CDM}}$. These two characteristic times are obtained for every cross-section. The centroid is clearly delayed with respect to the peak. Although in the front of the cloud the colorant may not be fully distributed across the section (cf figure $2(a)$ ), potentially biasing the results towards the crosssection maximum velocities, this does not seem relevant to concentration distribution, as seen in the first points captured in figure 3(a).

Figure $3(b)$ shows the time for the centroid for every position in the flume assessed longitudinally by the camera for the five slug injections conducted at a discharge rate of $Q=$ $5.01 \mathrm{~s}^{-1}$ without boulders present. The data are clearly aligned, and the results of the five colorant injections collapse well. The slope of the graph corresponds to the centroid velocity, which corresponds to the mean flow velocity. For $T_{\text {peak }}$, the same procedure described for figure $3(b)$ is applied. The technique employed for greyscale values (GL and CSGL) follows the same steps as those for $\mathrm{ED}_{\mathrm{RGB}}$ video analysis.

\section{Results and discussion}

To validate the velocity measurement techniques described in this study, the techniques are compared with three methods widely used to estimate open-channel flow velocities: salt tracer (using the centroid $S_{\mathrm{CDM}}$ and peak $S_{\text {peak }}$ methods), UVP and WD-based measurement. In the presence of macroroughness elements, the techniques described in section 4 can be compared only to the salt tracer method, due to difficulties associated with using the two other methods (cf section 1 and table 1). Table 3 shows the results of velocity measurements obtained for flows in the flume with and without boulders, along with those obtained with the other techniques and with the colorant-based methods.

For measurements carried out without boulders, flow velocities calculated with WD are slightly higher than those obtained with UVP. Table 3 clearly shows that in the absence of boulders, the peak velocity is closer to the WD velocity, while the centroid velocity is closer to the UVP velocity for all tracer analysis methods. The relative channel roughness is high ( $d_{m} / h$ is between 0.18 and 0.50 , where $h$ is the WD); thus, large errors in the WD measurements and consequently in the velocity calculations are expected.

In general, the peak velocity results obtained with the salt injection method and the three video analysis techniques 
Table 4. Velocity differences $\Delta$ (equation (2)) between the colorant-based velocity measurements ( $\mathrm{ED}_{\mathrm{RGB}}$, GL and CSGL) and the other techniques $\left(S_{\text {peak }}, S_{\mathrm{CDM}}, \mathrm{UVP}\right.$ and WD). Velocity values are given in table 3 . In the vertical, the grey cells correspond to the best result between $\mathrm{ED}_{\mathrm{RGB}}$, GL and CSGL and the other techniques.

\begin{tabular}{|c|c|c|c|c|c|c|c|c|c|}
\hline & & & & & & \multicolumn{4}{|c|}{$\Delta$ with boulders } \\
\hline & & \multicolumn{4}{|c|}{$\Delta$ without boulders } & \multicolumn{2}{|c|}{$\lambda / D=2$} & \multicolumn{2}{|c|}{$\lambda / D=3$} \\
\hline & & $S_{\mathrm{CDM}}$ & $S_{\text {peak }}$ & UVP & WD & $S_{\mathrm{CDM}}$ & $S_{\text {peak }}$ & $S_{\mathrm{CDM}}$ & $S_{\text {peak }}$ \\
\hline \multirow[t]{2}{*}{$\mathrm{ED}_{\mathrm{RGB}}$} & CDM & 0.030 & 0.121 & 0.051 & 0.105 & 0.069 & 0.205 & 0.017 & 0.202 \\
\hline & Peak & 0.143 & 0.022 & 0.096 & 0.053 & 0.213 & 0.049 & 0.423 & 0.133 \\
\hline \multirow[t]{2}{*}{ GL } & CDM & 0.129 & 0.225 & 0.164 & 0.212 & 0.202 & 0.318 & 0.129 & 0.316 \\
\hline & Peak & 0.139 & 0.021 & 0.092 & 0.051 & 0.193 & 0.050 & 0.349 & 0.088 \\
\hline \multirow[t]{2}{*}{ CSGL } & $\mathrm{CDM}$ & 0.031 & 0.137 & 0.074 & 0.123 & 0.107 & 0.241 & 0.077 & 0.234 \\
\hline & Peak & 0.125 & 0.006 & 0.079 & 0.028 & 0.210 & 0.054 & 0.314 & 0.070 \\
\hline
\end{tabular}

are similar. The same can be said for the centroid velocity estimates.

In the presence of boulders, the salt tracking method is considered to yield adequate velocity estimates. In this case, the peak and centroid velocities also correspond well for both tracers.

The differences between the peak and centroid velocities are smaller for the measurements obtained without boulders present. The increase in the differences in the velocities measured in the presence of boulders is most likely due to the impact of dead zones with low longitudinal velocities that are present downstream from boulders. This phenomenon is even more visible in the presence of sediment transport because of the scouring holes and recirculation zones that form downstream from boulders.

Table 4 compares the video analysis methods developed ( $\mathrm{ED}_{\mathrm{RGB}}, \mathrm{GL}$ and CSGL) with the other techniques. A variable $\Delta$ is introduced to express the deviation between the colorantbased velocity estimates $\left(v_{i, C}\right)$ and the estimates obtained with the other methods $\left(v_{i, M}\right)$. This parameter $\Delta$ takes into account the ensemble of the three discharges tested by means of a dimensionless averaged difference and is calculated as follows (equation (2)):

$$
\Delta=\frac{1}{3} \sum_{i=1}^{3}\left|\frac{v_{i, C}-v_{i, M}}{v_{i, M}}\right|,
$$

where $M$ indicates one of the measurement techniques ( $S_{\text {peak }}$, $S_{\mathrm{CDM}}$, UVP or WD) used for comparison with the colorant technique $C$ and $i$ indicates the discharge (from one to three). The absolute difference in the velocity values is normalized with respect to the result of the comparison technique. The average of the differences for every discharge is then used to validate the colorant techniques.

The results presented in table 4 show that the $\mathrm{ED}_{\mathrm{RGB}}$ estimates for the centroid velocity are closer to the results obtained by salt tracking (and to UVP in the absence of boulders, in grey in table 4) than the estimates obtained by GL and CSGL analysis for the same characteristic time. For peak velocities, the CSGL video analysis method results are generally closer to the salt tracking peak $\left(S_{\text {peak }}\right)$ velocity and to the WD results (in the absence of boulders).

As mentioned in section 1, most researchers agree on the use of the centroid velocity to evaluate average flow velocities. Thus, the RGB Euclidean distance $\left(\mathrm{ED}_{\mathrm{RGB}}\right)$, seems to be the best video analysis method, if the salt tracking centroid is taken as a reference.

With the technique developed in this study, using a single camera visualizing a $2.70 \mathrm{~m}$ long reach, local changes in velocity caused by the presence of boulders may be analysed. Furthermore, this measurement setup avoids the problems associated with selecting suitable cross-sections for measurements. With both salt tracer and dye tracer methods (using two video cameras), depending on the cross-sections selected, the presence of dead zones at the electrodes or the camera location can have an impact on the velocity estimation, as explained by Day (1976). Lastly, during sediment transport experiments, gravel bars are generally present in similar experiments and can occupy up to half of the flume width (Ghilardi and Schleiss 2012). Conductivity signals during measurements with the salt injection method are attenuated by the presence of such gravel bars. The same applies to the video analysis technique described by Recking et al (2008), applied in this study using the CSGL method (see section 4) because it takes into account the whole flume width in the video analysis. The GL and $\mathrm{ED}_{\mathrm{RGB}}$ techniques (see section 4) only analyse the part of the video where colorant has previously been detected, thus avoiding the weakening of the signal due to the flume's average cross-section, instead of the actual flow's average cross-section.

As can be seen in figure $3(b)$, there is a certain scatter in the time of arrival of the centre of mass at a given position. However, the error in $\mathrm{d} x / \mathrm{d} t$ seems to be smaller than $5 \%$ for the $\mathrm{ED}_{\mathrm{RGB}}, \mathrm{CDM}$. Our results are confirmed by other measurement techniques, confirming that the average velocity is tracked. However, the video should be captured downstream of the advective zone, as discussed above.

\section{Conclusions}

In steep channels, WD and morphology vary rapidly. It is therefore difficult to select representative cross-sections for measurements. The use of classical tracer techniques to estimate velocities between two (or more) cross-sections partially avoids the problem of cross-section selection. Nevertheless, it is necessary to avoid tracer measurements in dead water zones, which are often present in channels of this type. Measurements in dead zones produce long tails in tracer intensity measurements. The main advantage (cf table 1) of 
the method presented in this study is that it completely avoids this problem of cross-section selection. The position of the video camera allows the visualization and analysis of an entire reach $\left(0.25 \times 2.70 \mathrm{~m}^{2}\right)$ at one time. A global analysis of tracer transport can thus be conducted.

Three flow velocity estimation techniques based on video analysis of dye concentration were examined and validated. In the absence of macro-roughness elements, the results proved to be similar to those obtained with standard techniques such as WD and UVP measurements. Only the salt tracking method, which is widely used in steep flumes and mountain rivers, is also applicable in the presence of macro-roughness elements and was compared with the dye tracer technique for validation purposes. The method presented here proved to be valid, and the results were comparable.

Several video analysis methods were compared. The method developed in this study, which involves calculating the velocity of the centroid based on the RGB Euclidean distance $\mathrm{ED}_{\mathrm{RGB}}$, using only pixels with colorant, yielded the smallest differences with respect to the centroid velocity determined from salt injection. The latter is the most widely used technique for measuring water velocity in mountain rivers and steep channels.

Cross-section grey-level analysis using the whole image was found to yield results that are similar to peak velocities determined from salt injection. Because the whole crosssection is analysed in this data analysis method, the calculation is faster. However, gravel bars occupying more than half the cross-section are often present when working with a mobile bed and sediment supply on steep slopes. In this case, the amplitude of the signal is reduced. The presence of gravel bars covering the electrodes has the same impact on conductivity measurements when working with a saline tracer. This problem can be avoided using the measurement system and data analysis described in this study, which involves using the whole reach and analysing only the part of the cross-section where colorant is identified.

Other advantages of this innovative velocity measurement system are its simplicity and versatility. A simple video camera is used. The camera is positioned with the flow visualized in the horizontal video axis at a height of approximately $3.9 \mathrm{~m}$ above the water surface. The videotapes obtained are analysed by means of a computational procedure. No special light conditions are needed. Direct light on the flow must, however, be avoided and the image must not be too dark; otherwise the dark colorant (violet ink) might not be identified. The applicability of this velocity measurement technique to field measurements in small shallow mountain rivers could also be explored. However, depending on the local conditions (vegetation, light conditions, surface pattern, etc) it may be difficult to place the camera in order to visualize a long river reach. Finally, adequate vertical and transversal mixing of the colorant and assuring that the video is taken out of the advective zone are important issues in field measurements.

\section{Acknowledgments}

This work was supported by the Swiss Competence Center for Environmental Sustainability (CCES) of the ETH domain under the APUNCH project and the Swiss Federal Office of Energy (SFOE).

\section{References}

Amini A, De Cesare G and Schleiss A J 2009 Velocity profiles and interface instability in a two-phase fluid: investigations using ultrasonic velocity profiler Exp. Fluids 46 683-92

Blanckaert K and De Vriend H 2004 Secondary flow in sharp open-channel bends J. Fluid Mech. 498 353-80

Calkins D and Dunne T 1970 A salt tracing method for measuring channel velocities in small mountain streams J. Hydrol. 11 379-92

Cao S 1985 Résistance hydraulique d'un lit de gravier mobile à pente raide; étude expérimentale No 589 Ecole Polytechnique Fédérale de Lausanne (EPFL) p 318

Church M A and Kellerhals R 1970 Stream gauging techniques for remote areas using portable equipment Technical Bulletin no 25 Inland Waters Branch, Department of Energy, Mines and Resources $\mathrm{p} 90$

Davies T R H and Jäggi M N R 1981 Precise laboratory measurement of flow resistance XIX IAHR Congress (New Delhi, India) pp 463-71

Day T J 1976 On the precision of salt dilution gauging J. Hydrol. 31 293-306

Dugué V, Blanckaert K, Chen Q and Schleiss A J 2013 Reduction of bend scour with an air-bubble screen-morphology and flow patterns Int. J. Sediment Res. 28 15-23

Franca M J, Ferreira R M L and Lemmin U 2008 Parameterization of the logarithmic layer of double-averaged streamwise velocity profiles in gravel-bed river flows $A d v$. Water Resour. 31 915-25

Franca M J and Lemmin U 2006 Eliminating velocity aliasing in acoustic Doppler velocity profiler data Meas. Sci. Technol. 17313

Fujita I, Muste M and Kruger A 1998 Large-scale particle image velocimetry for flow analysis in hydraulic engineering applications J. Hydraul. Res. 36 397-414

Ghilardi T and Schleiss A J 2011 Influence of immobile boulders on bedload transport in a steep flume 34th IAHR World Congress (Brisbane, Australia, 26 June-1 July 2011) pp 3473-80

Ghilardi T and Schleiss A J 2012 Steep flume experiments with large immobile boulders and wide grain size distribution as encountered in alpine torrents Proc. River Flow 2012 (San José, Costa Rica, 5-7 September 2012) pp 407-14

Heyman J, Mettra F, Ma H and Ancey C 2013 Statistics of bedload transport over steep slopes: separation of time scales and collective motion Geophys. Res. Lett. 40 128-33

Hinze J O 1975 Turbulence 2nd edn (New York: McGraw-Hill) p 790

Jodeau M, Hauet A, Paquier A, Le Coz J and Dramais G 2008 Application and evaluation of LS-PIV technique for the monitoring of river surface velocities in high flow conditions Flow Meas. Instrum. 19 117-27

Kantoush S A, Schleiss A J, Sumi T and Murasaki M 2011 LSPIV implementation for environmental flow in various laboratory and field cases J. Hydro-environ. Res. 5 263-76

Kraus N, Lohrmann A and Cabrera R 1994 New acoustic meter for measuring 3D laboratory flows J. Hydraul. Eng. 120 406-12

Le Coz J, Hauet A, Pierrefeu G, Dramais G and Camenen B 2010 Performance of image-based velocimetry (LSPIV) applied to flash-flood discharge measurements in Mediterranean rivers $J$. Hydrol. 394 42-52

Le Coz J, Pierrefeu G and Paquier A 2008 Evaluation of river discharges monitored by a fixed side-looking Doppler profiler Water Resour. Res. 44 W00D09 
Leite Ribeiro M, Blanckaert K, Roy A G and Schleiss A J 2012 Flow and sediment dynamics in channel confluences $J$. Geophys. Res. 117 F01035

Lorke A and Wüest A 2005 Application of coherent ADCP for turbulence measurements in the bottom boundary layer $J$. Atmos. Ocean. Technol. 22 1821-8

MacVicar B J, Beaulieu E, Champagne V and Roy A G 2007 Measuring water velocity in highly turbulent flows: field tests of an electromagnetic current meter (ECM) and an acoustic Doppler velocimeter (ADV) Earth Surf. Process. Landf. 32 1412-32

Mattioli M, Alsina J M, Mancinelli A, Miozzi M and Brocchini M 2012 Experimental investigation of the nearbed dynamics around a submarine pipeline laying on different types of seabed: the interaction between turbulent structures and particles Adv. Water Resour. 48 31-46

Muste M, Fujita I and Hauet A 2008 Large-scale particle image velocimetry for measurements in riverine environments Water Resour. Res. 44 W00D19

Nezu I and Nakagawa H 1993 Turbulence in Open-Channel Flows (Rotterdam, The Netherlands: Balkema) p 281

Nogueira H I S, Adduce C, Alves E and Franca M J 2013 Image analysis technique applied to lock-exchange gravity currents Meas. Sci. Technol. 24047001

Pagliara S 2007 Influence of sediment gradation on scour downstream of block ramps J. Hydraul. Eng. 133 1241-8

Pagliara S and Chiavaccini P 2006 Flow resistance of rock chutes with protruding boulders J. Hydraul. Eng. 132 545-52

Pagliara S, Palermo M and Carnacina I 2010 Expanding pools morphology in live-bed conditions Acta Geophys. $59296-316$

Papanicolaou A N, Bdour A and Wicklein E 2004 One-dimensional hydrodynamic/sediment transport model applicable to steep mountain streams J. Hydraul. Res. 42 357-75

Pokrajac D, Campbell L, Nikora V, Manes C and McEwan I 2007 Quadrant analysis of persistent spatial velocity perturbations over square-bar roughness Exp. Fluids 42 413-23

Raffel M, Willert C E and Kompenhans J 1998 Particle Image Velocimetry: A Practical Guide (Berlin: Springer)
Recking A 2006 Etude expérimentale de l'influence du tri granulométrique sur le transport solide par charriage $\mathrm{No}$ 2006-ISAL-00113 Institut National Des Sciences Appliquées de Lyon, Lyon p 263

Recking A, Frey P, Paquier A and Belleudy P 2009 An experimental investigation of mechanisms involved in bed load sheet production and migration J. Geophys. Res. 114 F03010

Recking A, Frey P, Paquier A, Belleudy P and Champagne J-Y 2008 Bed-load transport flume experiments on steep slopes $J$. Hydraul. Eng. 134 1302-10

Rickenmann D 1990 Bedload transport capacity of slurry flows at steep slopes No 9065 ETH Zürich, Zürich p 249

Rickenmann D 2001 Comparison of bed load transport in torrents and gravel bed streams Water Resour. Res. 37 3295-05

Roy A G, Buffin-Belanger T, Lamarre H and Kirkbride A D 2004 Size, shape and dynamics of large-scale turbulent flow structures in a gravel-bed river J. Fluid Mech. 500 1-27

Rutherford J 1994 River Mixing (Chichester: Wiley) p 347

Smart G M and Jäggi M N R 1983 Sediment transport on steep slopes Mitteilungen No 64 VAW, ETH Zürich, Zürich p 96

Thomas L and Marino B 2012 Inertial density currents over porous media limited by different lower boundary conditions $J$. Hydraul. Eng. 138 133-42

USBR 1980 Hydraulic Laboratory Techniques US Department of the Interior, Bureau of Reclamation, Denver, CO, USA

van Prooijen B C and Uijttewaal W S J 2002 A linear approach for the evolution of coherent structures in shallow mixing layers Phys. Fluids 14 4105-14

Voulgaris G and Trowbridge J H 1998 Evaluation of the acoustic Doppler velocimeter (ADV) for turbulence measurements $J$. Atmos. Ocean. Technol. 15272

Weichert R B 2005 Bed morphology and stability in steep open channels Mitteilungen No 192 VAW, ETH Zürich, Zürich p 264

Wilcox A C and Wohl E E 2007 Field measurements of three-dimensional hydraulics in a step-pool channel Geomorphology 83 215-31

Yager E M, Kirchner J W and Dietrich W E 2007 Calculating bed load transport in steep boulder bed channels Water Resour. Res. 43 W07418 